\title{
AVALIAÇÃO DE BIOCOMBUSTÍVEIS LÍQUIDOS PARA USO COMO ENERGIA TÉRMICA E EM REDUÇÃO*
}

\author{
Rodrigo Alberto Moreira Gomes ${ }^{1}$ \\ Wagner da Silva Lima² \\ Osmar Carvalho Serra ${ }^{3}$ \\ Claudio Alexandre de Medeiros Lima ${ }^{4}$
}

\section{Resumo}

Uma planta piloto de $600 \mathrm{~kW}$ térmicos implantada para avaliar e testar vários combustíveis líquidos e sólidos foi utilizada para avaliação do desempenho de queima de dois tipos de biocombustíveis líquidos em chama oxidante e redutora. Os testes contaram com a parceria entre a Votorantim Metais e a EMBRAPII. Foram avaliados nestas condições de queima quatro biocombustíveis líquidos derivados de óleo vegetal e de pirólise rápida de biomassa. Os resultados mostraram que os óleos avaliados apresentam excelente desempenho em chama oxidante permitindo o ajuste de ar e temperatura de entrada do combustível para otimizar a queima, podendo os mesmos serem utilizados em processos industriais.

Palavras-chave: Biocombustível; Combustão; Pirólise; Energia renovável.

\section{EVALUATION OF LIQUID BIOFUELS FOR USE AS THERMAL ENERGY AND MINERAL REDUCTION}

\section{Abstract}

A pilot plant of 600 thermal $\mathrm{kW}$ constructed to evaluate and test various liquid and solid fuels was used to evaluate the performance of burning two kinds of liquid biofuels in oxidizing and reducing flame. A partnership between VM and EMBRAPII was carried out. These firing conditions were evaluated four liquid biofuels derived from vegetable oil and the fast pyrolysis of biomass. The results showed that the oils evaluated had excellent performance in oxidizing flame enabling adjustment of the air inlet temperature and fuel to optimize combustion, the same may be used in industrial processes.

Keywords: Biofuel; Combustion; Pyrolysis; Renewable energy.

1 Engenheiro mecânico, mestre em tecnologia mineral, Gerente Corporativo de Tecnologia em Energia e Planejamento Estratégico, Votorantim Metais, Belo Horizonte, MG, Brasil.

2 Engenheiro eletricista, doutor em engenharia elétrica, consultor em energia, Gerencia de Energéticos da Diretoria de Tecnologia, Votorantim Metais, São Paulo, SP, Brasil.

3 Mestre em Gerenciamento e Tecnologia Ambiental, consultor em combustão, CIMATEC/SENAI$B A$, Salvador, BA, Brasil.

4 Consultor técnico em combustão, CIMATEC/SENAI-BA, Salvador, BA, Brasil.

* Contribuição técnica ao $35^{\circ}$ Seminário de Balanços Energéticos Globais e Utilidades e $29^{\circ}$ Encontro de Produtores e Consumidores de Gases Industriais, 13 a 15 de agosto de 2014, São Paulo, SP, Brasil. 
Seminário de Energia \& Utilidades

$35^{\circ}$ Seminário de Balanços Energéticos

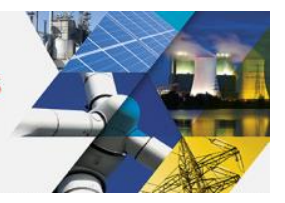

\section{INTRODUÇÃO}

A Votorantim Metais (VM) é grande consumidora de energia térmica em várias plantas industriais. Em geral esta energia térmica é utilizada em secagem de minérios, fornos de redução (combustível queimado em condições subestequiométricas), caldeiras (Á óleo, gás e coque de petróleo), calcinadores e outros usos.

Algumas das plantas da VM estão localizadas em Goiás (Niquelândia) e Minas Gerais (Três Marias), regiões de vocação agrícola e com disponibilidade para plantio de biomassa de alta produtividade a preços competitivos.

Numa primeira fase, de 2007 a 2010, a VM investiu recursos para a avaliação do uso de biomassa e seus derivados em seus processos industriais. Dentre as biomassas avaliadas estão as florestas de eucalipto adensadas e gramíneas energéticas como o capim elefante e a cana energia.

Foram realizados testes de campo com avaliações biométricas, colheita, baldeio e armazenamento. Entretanto, o uso de biomassa picada e com elevada umidade está quase sempre limitada à geração de vapor. Além disso, a baixa densidade energética $\left(G \mathrm{~J} / \mathrm{m}^{3}\right)$ da biomassa picada implica em aumento da complexidade das operações industriais e demanda espaço no sítio industrial, além de adaptação dos equipamentos e processos para recepção, armazenamento, manuseio e alimentação da biomassa nos processos industriais. Muitas vezes, estes espaços não estão disponíveis nas fábricas.

Desta forma, o mais adequado é substituir combustível líquidos por outro combustível liquido ou gás. Logo, numa segunda fase (de 2011 a 2013) a VM focou a analise da transformação da biomassa em combustíveis sólidos em combustíveis líquidos e gasosos. Dentre os destaques desta análise está a adequação da pirolise rápida de biomassa aos usos industriais de combustíveis, sobretudo na planta de Niquelândia, que atualmente queima coque de petróleo, óleo combustível e emulsões de coque e óleo. Não há gasodutos na região.

A pirólise rápida de biomassa é um processo de craqueamento térmico da biomassa realizado em reator leito fluidizado à temperatura em torno de $500{ }^{\circ} \mathrm{C}$ e com baixo teor de oxigênio ( 10\%). A biomassa é alimentada com umidade entre 5 e $10 \%$ (base úmida) com granulometria máxima de $5 \mathrm{~mm}$. Portanto, o processo exige a secagem e moagem da biomassa antes de entrar no reator de pirolise.

$\mathrm{O}$ produto imediato do reator de pirólise é um gás quente com particulados. $\mathrm{O}$ particulado contém carbono fixo associado que não volatizou no reator sendo recuperado através de um ciclone. Este carvão (ou bio-carvão) tem granulometria baixa e bom poder calorífico em torno de $5.800 \mathrm{kcal} / \mathrm{kg}$. Os gases restantes são resfriados em um condensador. Uma fração destes gases condensa e forma o bioóleo. Os gases não-condensáveis podem ser aproveitados em parte como make-up térmico do reator, na secagem de biomassa ou mesmo na geração de energia elétrica. Estes gases são redutores podendo ter concentração de CO de até $33 \%$ (Semelhante ao syngas dos processos de gaseificação).

O bio-óleo (fração líquida) possui poder calorífico que pode variar de 3.500 a 6.000 $\mathrm{kcal} / \mathrm{kg}$, dependendo da biomassa e da tecnologia de extração do mesmo. É possível diminuir o teor de água e de ácidos orgânicos no próprio condensador. Este óleo é composto por ácidos carboxílicos (Principalmente o ácido ascético), fenóis, furfurais, álcoois, aldeídos, lignina pirolítica, cetonas, hidrocarbonetos, água, carbono fixo (Uma parcela é coqueificável) e um pouco de cinzas (abaixo de 1\%) [1]. Além do poder calorifico baixo, o mesmo possui pH em torno de 3. O que implica em

* Contribuição técnica ao $35^{\circ}$ Seminário de Balanços Energéticos Globais e Utilidades e $29^{\circ}$ Encontro de Produtores e Consumidores de Gases Industriais, 13 a 15 de agosto de 2014, São Paulo, SP, Brasil. 


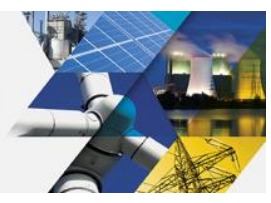

ter tanques de recebimento, tubulação e bombas dedicadas ao mesmo com proteção anti-corrosão não-convencionais.

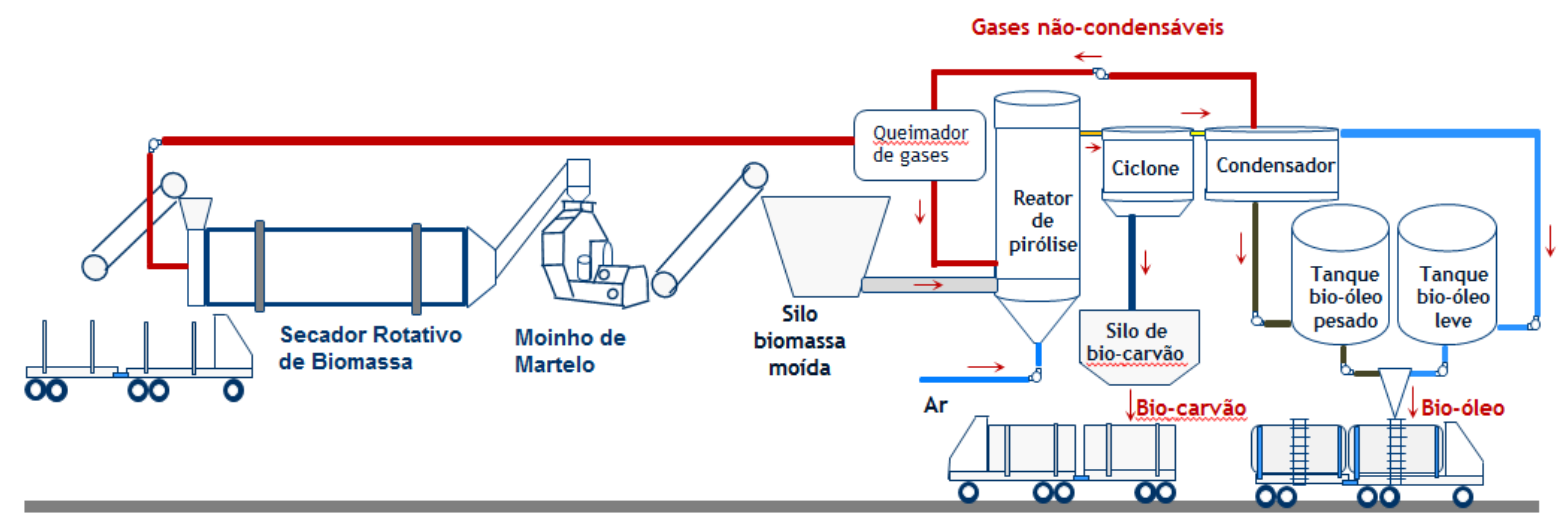

Figura 1. Processos para obtenção do bio-óleo (Pirólise rápida de biomassa)

Ao mesmo tempo, com o incentivo à produção de bio-diesel no Centro-Oeste e com o aumento da produção agrícola, principalmente de culturas oleaginosas, tem surgido no mercado empresas especializadas que utilizam resíduos industriais do beneficiamento destas culturas para oferecer óleos combustíveis alternativos de origem da indústria de óleo vegetal e bio-diesel condicionados com aditivos que permitem sua homogeneização. Diante destas oportunidades foi avaliado também o desempenho deste tipo de combustível renovável.

A VM construiu uma planta piloto de $600 \mathrm{~kW}$ térmicos na unidade de Niquelândia em Goiás para testes com queima de óleo combustível mineral em emulsões com coque de petróleo no período de 2007-2011. Através desta planta piloto foram realizados neste período experimentos com emulsões de coque de petróleo e óleos combustíveis diversos.

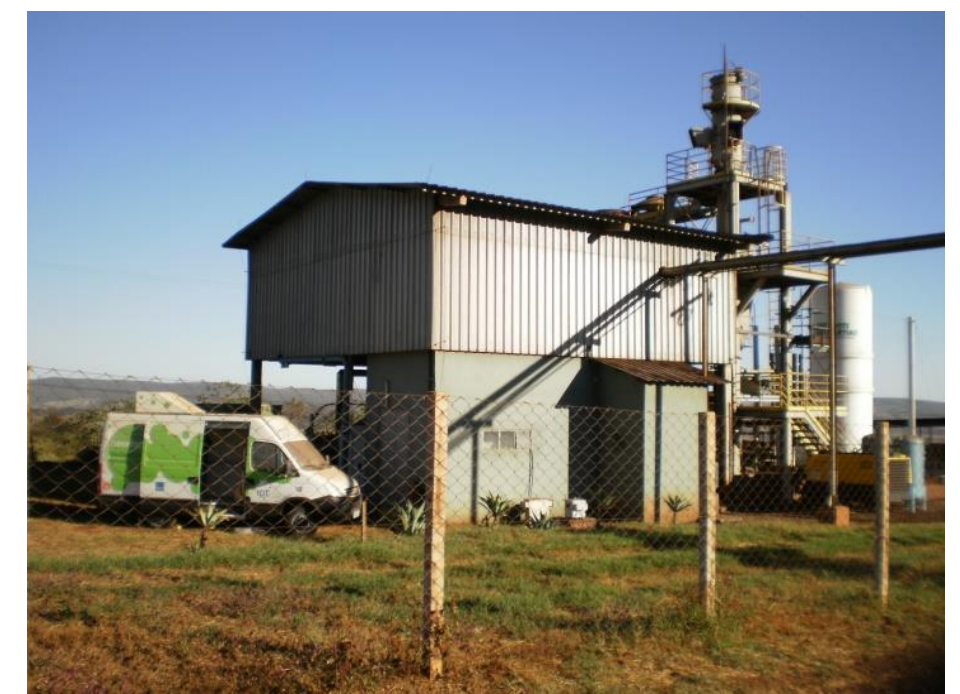

Figura 2. Planta piloto de combustão na VMN Niquelândia junto ao veiculo de monitoramento on-line de emissões do IPT

Nesta nova etapa, o grande desafio é a busca da redução de custos e uso de combustíveis renováveis mais baratos e alternativos ao gás natural e ao óleo combustível, visando também à redução de gases de efeito estufa.

* Contribuição técnica ao $35^{\circ}$ Seminário de Balanços Energéticos Globais e Utilidades e $29^{\circ}$ Encontro de Produtores e Consumidores de Gases Industriais, 13 a 15 de agosto de 2014, São Paulo, SP, Brasil. 


\section{MATERIAIS E MÉTODOS}

\subsection{Métodos}

Foi desenvolvida em 2013 uma parceria VM com a EMBRAPII (Empresa Brasileira de Pesquisa e Inovação Industrial) para a reforma da Planta Piloto em Niquelândia, desenvolvimento de um novo queimador multi-combustível, novo sistema de mistura de combustíveis, realização dos experimentos, monitoramento das variáveis de processo e de emissões e análise dos resultados.

O queimador multi-combustível foi desenvolvido pela DYNAMIS Mecânica Aplicada de São Paulo. O monitoramento das emissões foi realizado pelo IPT (Área de Energia Térmica) e a reforma da planta piloto e a realização dos experimentos, bem como, a análise dos resultados e documentação foi realizada pelo CIMATEC (SENAI-BA) contratados via EMBRAPII. A operação da planta piloto ficou à cargo da VM bem como o acompanhamento dos experimentos por seu corpo técnico especializado.

Determinou-se realizar experimentos de queima de combustíveis em atmosfera oxidante (com excesso de oxigênio) e redutora (condição sub-estequiométrica).

A combustão em atmosfera oxidante é utilizada nos secadores, calcinadores e processos que exigem apenas o fornecimento de energia térmica. A atmosfera redutora é para uso nos fornos de redução de minério de níquel e cobalto na planta de Niquelândia. São nove fornos tipo Nichols Herreshof que utilizam óleo combustível, sendo este o maior custo energético da planta [2].

Os experimentos foram realizados com uma programação pré-definida, sendo um dia para preparação do sistema (Limpeza da tubulação, queimador e instrumentos), carregamento do tanque de mistura, ajuste da queima até a condição de regime permanente, ajustando-se o ar primário e secundário, emissões de particulado, temperatura do óleo e comprimento de chama. Após chegar nesta condição o combustível foi queimado por 16 horas ininterruptas.

O registro dos dados de processo e das análises dos gases de combustão foi feito através de um sistema de aquisição automática de dados do IPT que guardava as informações a cada 10 segundos. Além desses registros, o operador da planta fazia o preenchimento de uma folha de leitura com frequência variando de uma a cada 20 ou 30 minutos.

A composição dos gases de combustão foi medida continuamente por analisadores de gases do tipo extrativo. Os gases analisados foram amostrados com uma sonda resfriada a água introduzida no ponto de amostragem situado mais próximo da saída da câmara de combustão. Para os testes em que a chama estava na condição oxidante, os componentes dos gases de combustão que eram analisados foram $\mathrm{O}_{2}$, $\mathrm{CO}, \mathrm{CO}_{2}$ e $\mathrm{NO}_{x}$. Para os testes com a chama na condição redutora, os componentes analisados foram $\mathrm{CO}_{2}, \mathrm{CO}$ e $\mathrm{H}_{2}$.

O monitoramento procurou avaliar as seguintes variáveis e parâmetros de processo:

- Vazão corrigida de combustível (kg/h);

- Vazão total ajustada Ar combustão (kg/h);

- Razão Ar tangencial/Ar axial;

- Vazão de vapor para queimador $(\mathrm{kg} / \mathrm{h})$;

- Temperatura do combustível $\left({ }^{\circ} \mathrm{C}\right)$;

- Temp. câmara de combustão $\left({ }^{\circ} \mathrm{C}\right)$;

- $\lambda$ (Ar real/Ar teórico).

* Contribuição técnica ao $35^{\circ}$ Seminário de Balanços Energéticos Globais e Utilidades e $29^{\circ}$ Encontro de Produtores e Consumidores de Gases Industriais, 13 a 15 de agosto de 2014, São Paulo, SP, Brasil. 


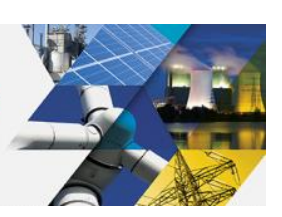

Foram também monitorados a composição gases de combustão:

- $\mathrm{CO}_{2}(\%$ BS);

- $\mathrm{CO}(\mathrm{ppm} \vee \mathrm{BS})$;

- $\mathrm{O}_{2}(\% \vee \mathrm{BS})$;

- $\mathrm{H}_{2}(\% \mathrm{BS})$;

- $\mathrm{NO}_{\mathrm{x}}(\mathrm{ppm} \vee \mathrm{BS})$;

- $\mathrm{NO}_{x}\left(\mathrm{mg} / \mathrm{Nm}^{3} @ 3 \% \mathrm{O}_{2}\right)$;

- Material particulado $\left(\mathrm{g} / \mathrm{Nm}^{3}\right)$.

\subsection{Materiais}

Foram avaliados o desempenho de queima de dois tipos de biocombustíveis líquidos em chama oxidante e chama redutora:

- Óleo derivado de óleos vegetais:

- ODOV;

- Óleos de pirólise rápida de biomassa:

○ RFO;

○ Bio-óleo bruto;

○ BPL.

O ODOV é um óleo combustível derivado principalmente da fração líquida do esmagamento de grãos.

O RFO (Renewable Fuel Oil) é um óleo combustível derivado de biomassa lenhosa como eucalipto e pinus. O mesmo é produzido pelo processo RTP (Rapid Thermal Processing) da ENSYN. Para os testes realizados com este combustível foram utilizados 3 toneladas para cada experimento. As amostras foram geradas nos EUA e enviadas à Niquelândia. Duas possibilidades foram avaliadas: o RFO filtrado e o RFO não filtrado [3].

Considerando o potencial de uso de gramíneas energéticas foram gerados também mais dois tipos de bio-óleo feitos a partir da cana energia (Fornecida pela VIGNIS Melhoramento Genético). As amostras destes bio-óleos foram gerados pela BIOWARE em Campinas, SP:

- Bio-óleo bruto: Com baixo teor de água (5\%) e sem o extrato ácido;

- BPL (Biomassa Liquida Padronizada): É o bio-óleo bruto com adição de $10 \%$ em peso de etanol (Para neutralização de pH e estabilização do bio-óleo) [4].

$\mathrm{Na}$ unidade de Niquelândia é utilizado o coque de petróleo como combustível para a caldeira, nos secadores de minério e em emulsões com óleo combustível nos fornos de redução. Desta forma também foram realizados experimentos de biocombustíveis misturados ao coque. Na Tabela 1 é apresentada a relação dos experimentos realizados.

* Contribuição técnica ao $35^{\circ}$ Seminário de Balanços Energéticos Globais e Utilidades e $29^{\circ}$ Encontro de Produtores e Consumidores de Gases Industriais, 13 a 15 de agosto de 2014, São Paulo, SP, Brasil. 
Tabela 1. Relação dos experimentos realizados

\begin{tabular}{|c|c|c|}
\hline & EXPERIMENTO & Atmosfera \\
\hline 1 & Óleo 2A & Oxidante \\
\hline 2 & ODOV & Oxidante \\
\hline 3 & BPL & Oxidante \\
\hline 4 & RFO filtrado & Oxidante \\
\hline 5 & RFO não-filtrado & Oxidante \\
\hline 6 & Bio-óleo sem extrato & Oxidante \\
\hline 7 & ODOV & Redutora \\
\hline 8 & RFO Filtrado & Redutora \\
\hline 9 & Bio BPF & Redutora \\
\hline
\end{tabular}

A composição química elementar e a umidade dos combustíveis são apresentadas na Tabela 2.

Tabela 2. Composição química elementar (\% massa seca) e umidade (base úmida) dos combustíveis avaliados

\begin{tabular}{l|c|cccccc}
\hline \multicolumn{1}{c|}{ COMBUSTÍVEL } & UMIDADE & C & H & O & N & S & CZ \\
\hline ÓLEO 2A & 0,50 & 89,70 & 9,10 & & 0,30 & 0,80 & 0,10 \\
ODOV & 0,40 & 76,10 & 10,60 & 13,30 & & & \\
BPL & 11,00 & 56,90 & 6,08 & 37,02 & & & \\
RFO & 24,00 & 54,87 & 6,67 & 38,25 & 0,16 & & 0,15 \\
BioPBF & 20,00 & 50,80 & 10,11 & 37,76 & & & 1,33 \\
Bio-óleo sem extrato & 14,00 & 51,50 & 6,94 & 41,46 & & & 0,10 \\
\hline
\end{tabular}

\section{RESULTADOS E DISCUSSÃO}

\subsection{Testes e Medições}

O Exprimento1 (Óleo 2A) é considerado o teste branco para determinar a linha de base para efeito de comparação.

\subsubsection{Atmosfera oxidante:}

Foram realizados seis experimentos com chama oxidante, sendo o primeiro para determinação da linha de base com óleo 2A. A Tabela 3 apresenta os valores médios das variáveis de processo.

Tabela 3. Valores médios de variáveis de processo e de composição dos gases de combustão

\begin{tabular}{lcccc} 
EXPERIMENTO & $\begin{array}{c}\text { Razão Ar } \\
\text { tangencial / } \\
\text { Ar axial }\end{array}$ & $\begin{array}{c}\text { Temp. } \\
\text { comb. }\end{array}$ & $\begin{array}{c}\text { Temp. } \\
\text { câmara } \\
\text { comb. } \\
{ }^{\circ} \mathrm{C}\end{array}$ & $\begin{array}{c}\boldsymbol{A} \\
\text { (Ar real / Ar } \\
\text { teórico) }\end{array}$ \\
\hline Óleo 2A & 0,32 & 60,0 & 1.280 & 1,11 \\
2 ODOV & 0,23 & 58,0 & 1.400 & 1,20 \\
3 BPL & 0,29 & 72,0 & 1.327 & 1,12 \\
4 RFO filtrado & 0,39 & 92,0 & 1.237 & 1,18 \\
5 RFO não-filtrado & 0,38 & 86,0 & 1.128 & 1,16 \\
6 Bio-óleo sem extrato & 0,32 & 67,0 & 1.370 & 1,32 \\
\hline
\end{tabular}

* Contribuição técnica ao $35^{\circ}$ Seminário de Balanços Energéticos Globais e Utilidades e $29^{\circ}$ Encontro de Produtores e Consumidores de Gases Industriais, 13 a 15 de agosto de 2014, São Paulo, SP, Brasil. 


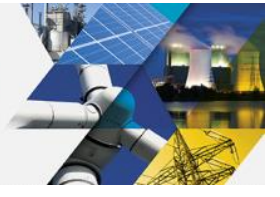

Verifica-se que todos os óleos apresentam boa temperatura de câmara. O melhor desempenho é do ODOV. O mesmo tem poder calorifico e outras características físico-químicas mais parecido com o óleo 2A. Entretanto sua viscosidade é menor e sua temperatura de armazenagem também é menor trazendo muitas vantagens em seu manuseio.

Em relação aos parâmetros Acendimento e Nebulização, observa-se que todos os combustíveis apresentaram facilidade de acendimento do queimador com o uso do piloto e que nem todos tiveram facilidade de nebulização com ar comprimido, exceto o RFO não filtrado. Entretanto, sua nebulização foi fácil com vapor.

Quanto aos parâmetros Armazenamento e Escoamento, o ODOV e o BPL foram os que apresentaram comportamento mais favorável, pois podem ser armazenados na temperatura ambiente e não apresentou nenhuma tendência a formar obstrução de linhas ou de qualquer outro elemento do sistema de combustível. Todos os demais combustíveis requerem leve aquecimento do tanque e homogeneização contínua durante a alimentação do queimador, para evitar estratificação.

O RFO filtrado e o RFO não filtrado requerem também que esse aquecimento seja feito sob controle rigoroso de temperatura $\left(\mathrm{t}<40^{\circ} \mathrm{C}\right)$, para evitar a formação de polímero e obstrução de elementos do sistema.

O ODOV e o BPL apresentaram baixa ou nenhuma tendência de acumular sujeira na rosácea do queimador. Entretanto, os RFOs e Bio Óleo (sem extrato) apresentam esta tendência. Isto ocorre devido a não homogeneização dos óleos e necessita com certeza de aditivos para sua queima. No RFO não-filtrado o acumulo é de material pastoso e no BIO-OLEO há formação de coque.

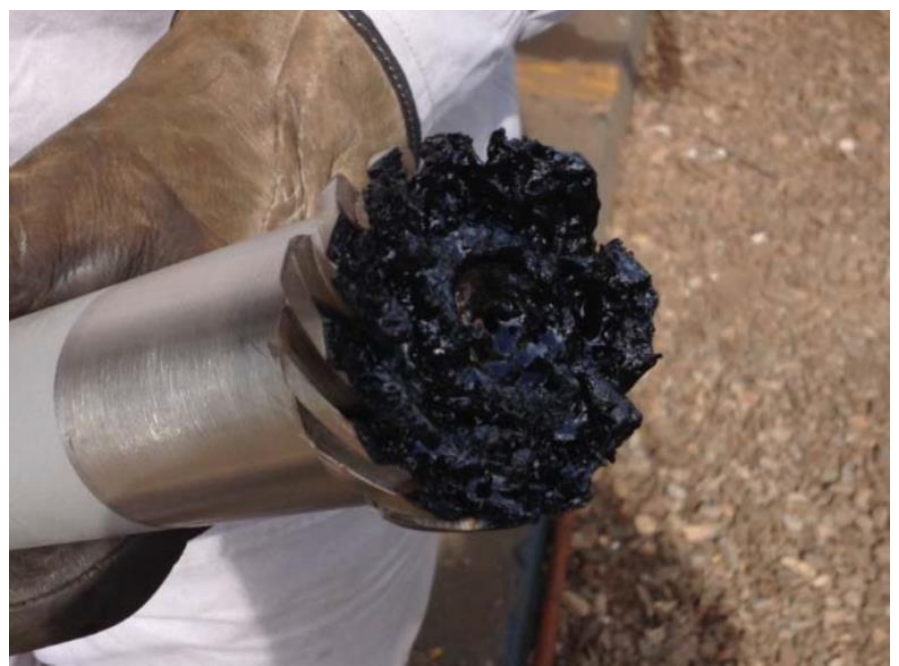

Figura 3. Formação de material pastoso no queimador na combustão do RFO não-filtrado

A Tabela 4, abaixo, apresenta o comportamento dos combustíveis quanto à elevação da temperatura da câmara de combustão, tendência a formar sujeira no queimador e o ajuste de $\mathrm{O}_{2}$ para que o $\mathrm{CO}$ fique abaixo de 50 ppm.

* Contribuição técnica ao $35^{\circ}$ Seminário de Balanços Energéticos Globais e Utilidades e $29^{\circ}$ Encontro de Produtores e Consumidores de Gases Industriais, 13 a 15 de agosto de 2014, São Paulo, SP, Brasil. 


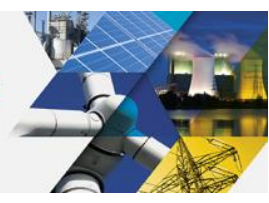

Tabela 4. Desempenhos dos bio-combustiveis em chama oxidante

\begin{tabular}{lccc} 
Combustível & $\begin{array}{c}\text { Ajuste da combustão } \\
\text { (excesso de } 02 \text { para que } \\
\text { o CO fique }<50 \mathrm{ppm})\end{array}$ & $\begin{array}{c}\text { Elevação temperatura } \\
\text { da câmara de } \\
\text { combustão }\end{array}$ & $\begin{array}{c}\text { Tendência a formar sujeira } \\
\text { no queimador }\end{array}$ \\
\hline Óleo 2a & $>2 \%$ & Rápida & Baixa \\
\hline ODOV & $>3 \%$ & Rápida & Baixa \\
\hline BPL & $>4,5 \%$ & Moderada & Baixa \\
\hline RFO filtrado & $>1 \%$ & Muito lenta & $\begin{array}{l}\text { Grande tendência em } \\
\text { obstruir o queimador com } \\
\text { acumulo de material } \\
\text { pastoso }\end{array}$ \\
\hline RFO não-filtrado & $>1 \%$ & $\begin{array}{l}\text { Moderada tendência em } \\
\text { obstruir o queimador com } \\
\text { depósito de coque }\end{array}$ \\
\hline $\begin{array}{l}\text { Bio óleo sem } \\
\text { extrato }\end{array}$ & $>5 \%$ & Rápida & \\
\hline
\end{tabular}

Observa-se que para o ODOV, BPL e RFO filtrado os resultados apontam o uso industrial sem nenhuma ressalva.

Em relação às emissões, a Tabela 5 apresenta as medições dos gases de combustão.

Tabela 5. Monitoramento dos gases de combustão, chama oxidante

\begin{tabular}{|c|c|c|c|c|c|}
\hline EXPERIMENTO & $\begin{array}{l}\mathrm{CO}_{2} \\
\% \vee B S \\
\end{array}$ & $\begin{array}{c}\text { CO } \\
p p m \vee B S\end{array}$ & $\begin{array}{c}\mathrm{O}_{2} \\
\% v B S \\
\end{array}$ & $\begin{array}{c}\text { NOx } \\
p p m v B S\end{array}$ & $\begin{array}{c}\text { NOx } \\
m g / \mathrm{Nm}^{3} @ 3 \% \mathrm{O}_{2} \\
\end{array}$ \\
\hline 1 Óleo 2A & 14,9 & 35 & 2,2 & 447 & 880 \\
\hline 2 ECOFIRE & 13,1 & 46 & 3,7 & 132 & 204 \\
\hline 3 BPL & 17,0 & 90 & 2,3 & 241 & 344 \\
\hline 4 RFO filtrado & 16,5 & 23 & 3,3 & 158 & 238 \\
\hline 5 RFO não-filtrado & 17,1 & 21 & 3,0 & 159 & 236 \\
\hline 6 Bio-óleo sem extrato & 14,5 & 53 & 5,2 & 223 & 377 \\
\hline
\end{tabular}

Observamos uma nítida menor emissão de $\mathrm{NO}_{x}$ com a queima dos biocombustíveis, chegando a ser metade ou menos da emissão da queima de óleo combustível.

\subsection{Atmosfera Redutora}

Os experimentos com chama redutora tiveram o objetivo de avaliar o desempenho desses combustíveis para utilização como fonte de geração de gás redutor (CO + $\mathrm{H}_{2}$ ) a ser utilizado nos fornos de redução. A característica principal dos gases de saída na chaminé é o aparecimento de chama pela queima dos gases redutores ao entrar em contato com o oxigênio do ar atmosférico.

Para ser viável tecnicamente utilizar o combustível nos fornos de redução a concentração mínima de $\mathrm{CO}+\mathrm{H}_{2}$ deve ser de $25 \%$ em volume.

* Contribuição técnica ao $35^{\circ}$ Seminário de Balanços Energéticos Globais e Utilidades e $29^{\circ}$ Encontro de Produtores e Consumidores de Gases Industriais, 13 a 15 de agosto de 2014, São Paulo, SP, Brasil. 

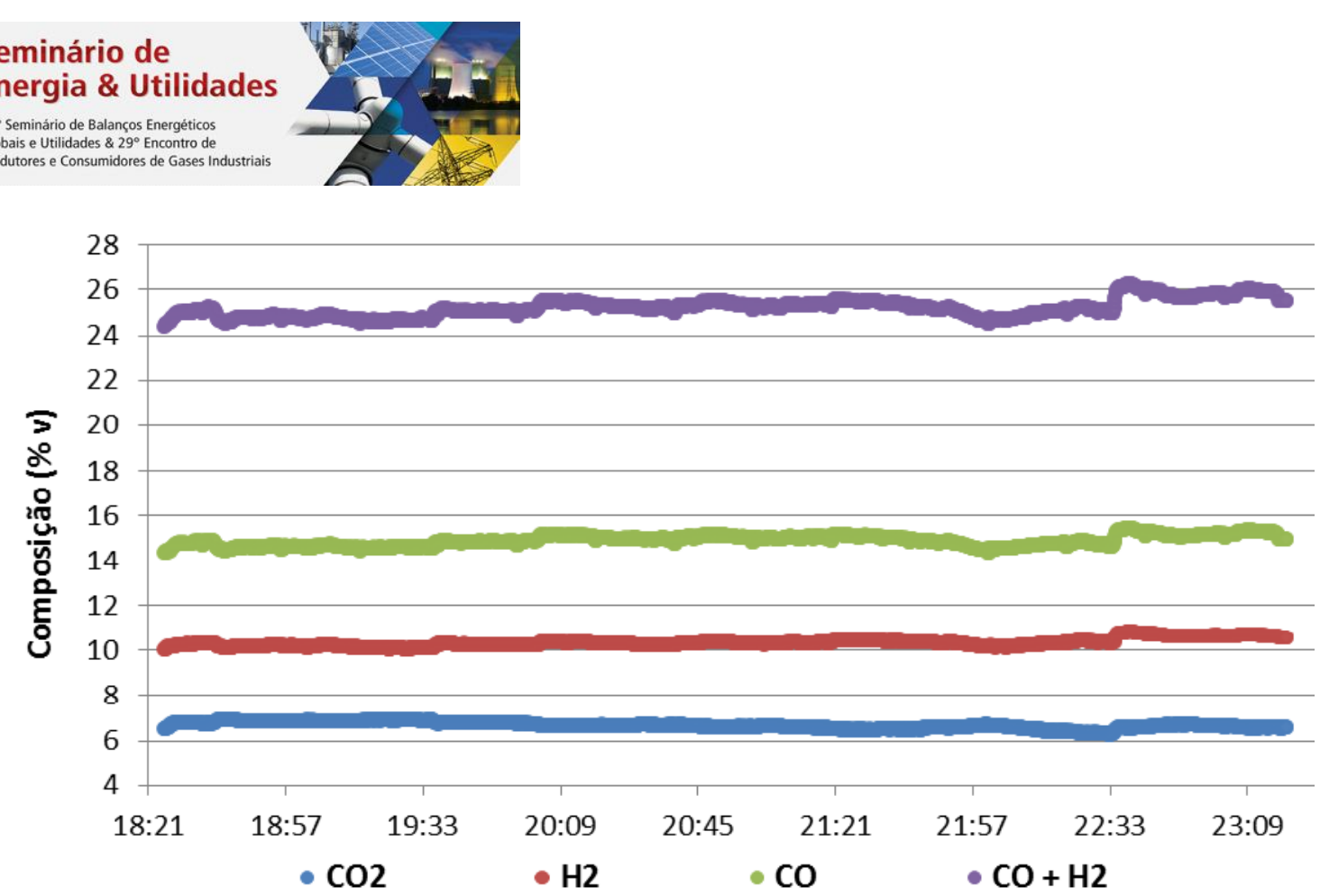

Figura 5. Composição volumétrica dos gases de combustão durante a combustão do ODOV em chama redutora.

A Tabela 6 apresenta o resultado de quatro parâmetros que foram avaliados nos testes com dois combustíveis simples que foram testados na Planta Piloto em chama redutora.

Tabela 6. Parâmetros de desempenho dos combustíveis simples em chama redutora

\begin{tabular}{l|l|c|c|c}
\hline \multirow{2}{*}{ COMBUSTívEL } & \multirow{2}{*}{$\begin{array}{c}\text { AJUSTE DA COMBUSTÃo } \\
\text { EM CHAMA REDUTORA }\end{array}$} & \multicolumn{3}{|c}{ MELHORES RESULTADOS ALCANÇADOS } \\
\cline { 4 - 5 } & $\lambda$ & $\begin{array}{c}\text { Soma concentração } \\
\text { de CO e } \mathrm{H}_{2}(\% \mathrm{v} \text { BS) }\end{array}$ & $\begin{array}{c}\text { Rendimento CO }+\mathrm{H}_{2} \\
\text { (mol/kg comb. BU) }\end{array}$ \\
\hline ODOV & $\begin{array}{l}\text { Sem dificuldade de ajuste } \\
\text { Temperatura estável da } \\
\text { câmara de combustão }\end{array}$ & 0,58 & 25,00 & 73,90 \\
\hline RFO filtrado & $\begin{array}{l}\text { Muita dificuldade de ajuste } \\
\text { Queda da temperatura da } \\
\text { câmara de combustão }\end{array}$ & 0,70 & 16,00 & 22,80 \\
\hline
\end{tabular}

Para os dois combustíveis em atmosfera redutora, não há formação de sujeira no queimador.

Observando-se esses parâmetros, percebe-se que o ODOV foi superior aos demais combustíveis em todos os quesitos, tanto nos operacionais quanto nos de geração do gás de redução $\left(\mathrm{CO}\right.$ e $\left.\mathrm{H}_{2}\right)$.

Ainda em relação ao rendimento de $\mathrm{CO}+\mathrm{H}_{2}$, o ODOV apresentou desempenho cerca de três vezes maior. Deve-se destacar, porém, que nos testes foi possível realizar a combustão do ODOV $\operatorname{com} \lambda$ um pouco menor que 0,6 , enquanto que a combustão do RFO filtrado somente pôde ser feita com $\lambda$ bem acima desse valor de referência. Isto foi possível provavelmente em função do maior poder calorífico e do teor de umidade do combustível.

A gaseificação dos bio-óleos deve ser considerada com mais cuidado, levando em conta outros resultados encontrados na literatura [5]. Melhores ajustes dos parâmetros desta gaseificação devem ser consideradas principalmente devido a presença de água em sua composição.

* Contribuição técnica ao $35^{\circ}$ Seminário de Balanços Energéticos Globais e Utilidades e $29^{\circ}$ Encontro de Produtores e Consumidores de Gases Industriais, 13 a 15 de agosto de 2014, São Paulo, SP, Brasil. 


\section{CONCLUSÃo}

Os resultados apresentados neste artigo apontam para uma estratégia de suprimento de ODOV para a unidade industrial, pois este combustível tem características bem próximas do óleo combustível mineral atualmente utilizado.

Além do bom poder calorifico, a não necessidade de aquecimento para armazenamento, a baixa viscosidade e a menor emissão de $\mathrm{NO}_{x}$ foram comprovadas nos experimentos realizados.

Em chama redutora o ODOV atingiu a concentração mínima para ser utilizado nos fornos de redução.

Os bio-óleos derivados de pirolise rápida de biomassa podem apresentar restrições quanto ao seu uso quando utilizados em sua forma bruta. Desta forma, o RFO e o BPL são indicados para combustão completa em atmosfera oxidante, pois são combustíveis de melhor qualidade. Dentre suas vantagens estão as baixas temperatura de armazenamento, emissão de $\mathrm{NO}_{x}$ e viscosidade.

$\mathrm{O}$ menor $\mathrm{pH}$ não afeta a questão da combustão e não há restrições desde que a estequiometria e a temperatura de queima estejam adequados. Caso se resolva utilizar os bio-óleo em forma bruta (Da mesma forma com que sai do condensador), a formação de borras pode ser evitada com aditivos.

A mistura do etanol foi benéfica ao bio-óleo, reduzindo seu odor, trazendo estabilidade e adquirindo características semelhantes ao ODOV, exceto o poder calorifico, que é a metade deste último.

O uso de bio-óleos brutos tiveram como desvantagem a formação de borras e coque no queimador, o que implicaria em diversas paradas de manutenção. Assim, o RFO filtrado e o BPL são adequados ao suprimento de calor industrial.

No intento de uso de fontes renováveis de energia, os bio-óleos são alternativas para a indústria metalúrgica. Culturas energéticas de elevada produtividade agrícola, como a cana energia, definem uma boa estratégia de suprimento de bio-óleo. Uma planta de bio-óleo pode ser construída nas proximidades da unidade fabril permitindo a escolha de melhores áreas de plantio.

O ODOV como oportunidade de curto e médio prazo destaca-se como uma excelente opção no mercado. Entretanto, para o logo-prazo, como a produção do ODOV depende do mercado de óleo vegetais e bio-diesel sua disponibilidade pode ser afetada pela dinâmica destes mercados que não tem correlação com o mercado de metais.

\section{Agradecimentos}

Agradecemos à FIBRIA, ENSYN, SENAI, IPT, DYNAMIS, BIOWARE e VIGNIS, além de toda a equipe operacional e administrativa da planta de Niquelândia, engenharia e tecnologia da VM pela realização deste trabalho.

\section{REFERÊNCIAS}

1 Bridgwater AV, Czernick S, Pirkorz J. An overview of fast pyrolysis. In: Progress in Thermochemical Biomass Conversion. Blackwell Sciences Ltd.; 2001, p. 997.

2 Silveira MC, Souza JE, Cavalcante PABH, Cruz TF, Noqueira JE, Gomes CG, et al. Queima de emulsão de óleo $2 \mathrm{~A}$ + coque de petróleo é pioneira no mundo. Revista Minérios \& Minerales. 2014; ano XXXVIII(359):60-62.

* Contribuição técnica ao $35^{\circ}$ Seminário de Balanços Energéticos Globais e Utilidades e $29^{\circ}$ Encontro de Produtores e Consumidores de Gases Industriais, 13 a 15 de agosto de 2014, São Paulo, SP, Brasil. 


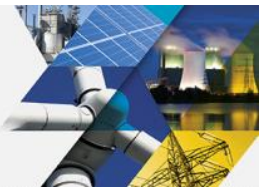

3 Soriano D. White Paper on Renewable Fuel Oil (RFO) Usage in Indurating Furnaces. Brais, Malouin and Associates Inc. 15 0. 2013.

4 Perez JM, Rodriguez RAV, Mesa HRM, Rocha, JD, Samaniego MRP, Cortez LAB. Bioflex obtido da pirólise de biomassa como combustível. In: Anais do 6º Encontro Energia no Meio Rural; 2006.

5 Filizola AR. Desenvolvimento de Nanocatalisadores Ativos na Gaseificação de BioÓleos [dissertação de mestrado]. Campinas: Instituto de Física Gleb Wataghin, UNICAMP; 2013. 